\title{
The changing landscape of opioid prescribing: long-acting and extended-release opioid class-wide Risk Evaluation and Mitigation Strategy
}

This article was published in the following Dove Press journal:

Therapeutics and Clinical Risk Management

28 April 2012

Number of times this article has been viewed

\author{
Jeffrey A Gudin \\ Englewood Hospital and Medical \\ Center, Englewood, NJ, USA
}

Correspondence: Jeffrey A Gudin Englewood Hospital and Medical Center, 350 Engle Street, Englewood, NJ, USA 0763I

Email healthmd@optonline.net

\begin{abstract}
Prescriptions for opioid analgesics to manage moderate-to-severe chronic noncancer pain have increased markedly over the last decade, as have postmarketing reports of adverse events associated with opioids. As an unintentional consequence of greater prescription opioid utilization, there has been the parallel increase in misuse, abuse, and overdose, which are serious risks associated with all opioid analgesics. In response to these concerns, the Food and Drug Administration announced the requirement for a class-wide Risk Evaluation and Mitigation Strategy (REMS) for long-acting and extended-release (ER) opioid analgesics in April 2011. An understanding of the details of this REMS will be of particular importance to primary care providers. The class-wide REMS is focused on educating health care providers and patients on appropriate prescribing and safe use of ER opioids. Support from primary care will be necessary for the success of this REMS, as these clinicians are the predominant providers of care and the main prescribers of opioid analgesics for patients with chronic pain. Although currently voluntary, future policy will likely dictate that providers undergo mandatory training to continue prescribing medications within this class. This article outlines the elements of the class-wide REMS for ER opioids and clarifies the impact on primary care providers with regard to training, patient education, and clinical practice.
\end{abstract}

Keywords: long-acting opioid, extended-release opioid, risk, REMS, FDA, primary care

\section{Introduction}

Prescription opioid analgesics have gained acceptance as effective treatments for moderate-to-severe chronic noncancer pain in properly selected patients. ${ }^{1,2}$ In 2009 , approximately 23 million prescriptions of the extended-release (ER) opioid class were dispensed to more than 3.8 million unique patients. ${ }^{3}$ However, an unintentional consequence of greater prescription opioid utilization has been the parallel increase in misuse, abuse, and overdose, which are serious risks associated with all opioid

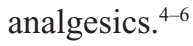

The Food and Drug Administration (FDA) has recognized the substantial risks associated with improper use of ER opioid formulations, given the large amount of active ingredient contained within a dose and the prolonged time to elimination..$^{7-11}$ Under the authority of the Food and Drug Administration Amendments Act of 2007, and as a result of stakeholder, industry, public, and advisory committee meetings held over several years, in April 2011 the FDA announced a class-wide Risk Evaluation and Mitigation Strategy (REMS) for ER opioid analgesics. ${ }^{12}$ A REMS is a required risk management plan that utilizes tools beyond routine labeling to ensure that the benefits 
of a medication outweigh the risks. ${ }^{13}$ The intent of the classwide REMS is to ensure that the therapeutic benefits of ER opioid formulations continue to outweigh the risks, particularly addiction, unintentional overdose, and death resulting from inappropriate prescribing, abuse, and misuse. ${ }^{12}$ Although provider participation in this REMS is currently voluntary to prescribe these drugs, the FDA and the US Government are pursuing legislation to mandate prescriber education as part of Drug Enforcement Administration licensing or renewal., ${ }^{8,14}$

The requirements of the class-wide REMS for ER opioids are particularly relevant to primary care providers, who prescribe approximately half of these medications ${ }^{3}$ and thus represent a key point of intervention for risk management and safe use. This article briefly reviews the scope of public health issues related to prescription opioids, describes the class-wide REMS for ER opioids, and answers a few common questions regarding this policy. Understanding this REMS will help clinicians navigate the rapidly evolving landscape for prescribing opioids.

\section{Overdose}

Drug overdose deaths have increased each year since 1970, and rates of overdose have increased five-fold since $1990 .{ }^{4}$ In 2007 , for example, more than 27,000 people died from unintentional drug overdose, ranking second only to car accidents as the leading cause of unintentional death due to injury in the US. ${ }^{4}$ Although rates of overdose have increased for illicit drugs such as cocaine and heroin, the most dramatic increase has been observed with prescription opioid medications. ${ }^{4}$ Recent epidemiologic data inclusive of patients with chronic noncancer pain, chronic cancer pain, and acute pain indicate an increased risk of overdose and overdose-related deaths in patients prescribed $\geq 50 \mathrm{mg}$ morphine equivalent per day. ${ }^{15,16}$ In chronic pain patients receiving $\geq 100 \mathrm{mg}$ morphine equivalent per day, the risk of overdose death was more than seven times that of chronic pain patients receiving $<20 \mathrm{mg}$ per day. ${ }^{15}$

\section{Misuse and abuse}

In 2009, approximately 5 million people reported prescription opioid abuse. ${ }^{5}$ In persons 12 years or older, the number of first-time abusers of prescription opioids was nearly as common as the number of first-time abusers of marijuana. ${ }^{5}$ In patients receiving opioids for chronic pain conditions, estimates of the prevalence of abuse in pain management settings range from $12 \%$ to $43 \% .{ }^{17-20}$ Furthermore, in primary care chronic pain patients receiving long-term opioid therapy, addiction was four times more likely compared with rates in the general population. ${ }^{21}$

In this same patient population, $80 \%$ of patients report at least one lifetime aberrant drug behavior (eg, request for early refills, unauthorized dose escalation). ${ }^{22}$ Furthermore, those who engaged in certain aberrant behaviors (purposely oversedating oneself, using opioids for nonpain reasons, escalating dose without authorization, or feeling intoxicated from opioid administration) were approximately 50 times more likely to have opioid addiction. ${ }^{21}$ Certain patient characteristics may also predict abuse, such as a history of substance use or comorbid psychological conditions, lending weight to the clinical value of utilizing risk assessment prior to initiating opioid therapy. ${ }^{23-27}$

A considerable majority $(88 \%)$ of persons who abuse prescription opioids obtain them from a friend, relative, or a single health care provider (Figure 1 ).${ }^{5}$ Furthermore, $18 \%$ of all persons who abuse a prescription opioid indicate that the drug was obtained from a single physician. Of the $55 \%$ of cases in which the drug was obtained from a friend or family member for free, that friend or relative obtained the prescription from a single health care provider more than $80 \%$ of the time. ${ }^{5}$ Safe

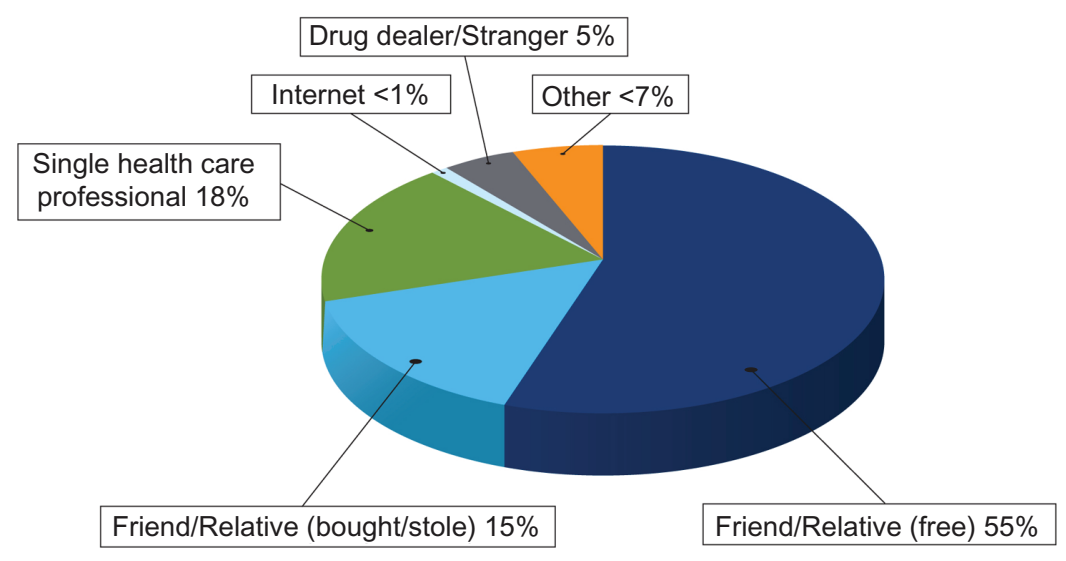

Figure I Sources of prescription opioid analgesics. Data from US Department of Health and Human Services. ${ }^{5}$ 
and appropriate prescribing practices are therefore fundamental to any risk mitigation effort associated with prescribing opioid analgesics (see Appendix 1). Accordingly, counseling patients on the importance of protecting their medication from theft and never sharing with others is critical.

\section{Class-wide REMS for ER opioids Overview of REMS}

A REMS may be required to ensure that the benefits of a medication outweigh the risks. ${ }^{13}$ Each REMS may have up to five components: (1) medication guide;

Table I Potential components of a REMS 13,39

\begin{tabular}{|c|c|c|}
\hline Components $^{a}$ & Purpose & Content and potential requirements \\
\hline $\begin{array}{l}\text { Medication } \\
\text { guide }\end{array}$ & Patient education & $\begin{array}{l}\text { - Product-specific risks and safety } \\
\text { information }\end{array}$ \\
\hline $\begin{array}{l}\text { Communication } \\
\text { plan }\end{array}$ & Provider education & $\begin{array}{l}\text { - Importance of the REMS } \\
\text { - Product-specific risks } \\
\text { - Protocols for safe use } \\
\text { (eg, patient monitoring) }\end{array}$ \\
\hline ETASU & $\begin{array}{l}\text { Safe access to medications } \\
\text { that would otherwise } \\
\text { be unavailable }\end{array}$ & $\begin{array}{l}\text { Potential elements: } \\
\text { - Provider training, experience, } \\
\text { or special certification to prescribe } \\
\text { - Provider training, experience, } \\
\text { or special certification to dispense } \\
\text { - Dispense only in certain health care } \\
\text { settings } \\
\text { - Dispense only to patients with safe-use } \\
\text { documentation } \\
\text { - Perform monitoring and follow-up } \\
\text { - Patient enrollment in a registry }\end{array}$ \\
\hline
\end{tabular}

Implementation system $^{d}$

Timetable for submission of assessments $^{\mathrm{e}}$ ETASU, the REMS may also require an implementation system to pre-emptively ensure compliance
If a REMS includes certain
- Ensure compliance with certification prior to prescribing or dispensing

- Restrict dispensing only in authorized safe-use health care settings or patients

- Restrict distribution only to preauthorized entities
Determine whether REMS is meeting desired goals
- Periodic assessments of the effectiveness of the overall program and each component
Examples of implementation

- Distributed at the pharmacy to patients when dispensing or filling a medication

- "Dear Health Care Professional" letters

- Professional society venue

- Providers demonstrate ability to diagnose and an understanding of the risks and benefits; may act as a prerequisite for prescribing

- Personnel dispensing the medication demonstrate an understanding of risks and benefits and/or agree to dispense only after receiving authorization

- Medication is dispensed only in the hospital

- Medication is given only to patients with safe-use documentation of counseling or appropriate laboratory results

- Monitoring is carried out at specific time points to prevent a serious risk

- Registry documents adherence to safe-use conditions or appropriate monitoring (eg, S.T.E.P.S. for thalidomide access) ${ }^{c, 28}$

- Validated and secure database of prescribers, pharmacies, and health care settings to verify certification requirements prior to prescribing and dispensing

- Manufacturer conducts periodic audits of prescribers, pharmacies, and health care settings to ensure compliance with safeuse conditions prior to dispensing

- Manufacturer conducts periodic audits of shipment or distribution systems to ensure that only preauthorized entities (eg, prescribers, pharmacies, health care settings) receive the medication

- Survey of provider knowledge of product risks and safe-use conditions

- Survey for appropriate patient use to prevent risk

- Survey of medication use (eg, provider specialty, indication)

- Surveillance to detect rates of specific serious adverse events

Notes: ${ }^{a} A$ REMS may not require all five components, and can be approved with only those that sufficiently mitigate the risk; ball elements may not be required if REMS is approved with ETASU; 'S.T.E.P.S. provider and patient registry to prevent fetal exposure and reduce risk of serious birth defects; ${ }^{d}$ for REMS that includes certain ETASU (see FDA Guidance, 505-I(f)(3)(B)(C)(D)), the implementation system is designed to monitor and evaluate the REMS and allows the ability to improve the REMS implementation. A critical part of the implementation system is that the FDA may require limited distribution of the product (ie, the product is distributed only when safe-use conditions are met,

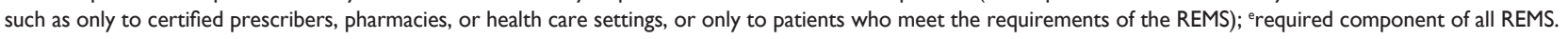
Abbreviations: ETASU, elements to assure safe use; FDA, Food and Drug Administration; REMS, Risk Evaluation and Mitigation Strategy; S.T.E.P.S., System for Thalidomide Education and Prescribing. 
(2) communication plan; (3) elements to assure safe use; (4) implementation system; and (5) timetable for submission of assessments (Table 1). ${ }^{13,39}$ Each REMS is individualized and approved with those components that address a product's therapeutic profile (Figure 2). ${ }^{13,29}$

\section{History and requirements of class-wide REMS for ER opioids}

The FDA indicated a need for a class-wide REMS for ER opioids as early as 2009..$^{12,30}$ In 2010, product-specific, interim REMS were approved for the ER formulation of hydromorphone (Exalgo ${ }^{\circledR}$; Mallinckrodt Inc, Hazelwood, $\mathrm{MO}$ ), a novel formulation of controlled-release oxycodone (OxyContin ${ }^{\circledR}$; Purdue Pharma LP, Stamford, CT), and transdermal buprenorphine (Butrans ${ }^{\circledR}$; Purdue Pharma LP). ${ }^{29}$ These programs provide patient education through a medication guide and health care professional training (eg, training on appropriate prescribing practices). ${ }^{29}$ In April 2011, the FDA officially announced the class-wide REMS for ER opioids, designed to mitigate serious risks of opioid-related adverse outcomes through provider training and patient education (see Appendix 2). ${ }^{12}$ The release of this policy was closely coordinated with the White House Office of National Drug Control Policy and formed an integral part of the comprehensive Prescription Drug Abuse Prevention Plan. ${ }^{14}$ The expected requirements of the new class-wide REMS for ER opioids are similar to those of the previously approved REMS for products in this class. ${ }^{12}$ However, in order to streamline provider and patient education and to decrease the burden on the health care system, all products within the ER opioid class will have the same REMS components. ${ }^{12}$ These components are discussed in greater detail in the following sections, with regard to the provider and patient perspectives.

\section{Medication guide}

A patient medication guide will describe risks (eg, abuse, overdose) and safe use, and stress adherence to the prescribed dosing regimen. ${ }^{12}$ In addition to specific information on safe and effective use of the particular opioid, the medication guide will include common language for all products in the class. ${ }^{12}$

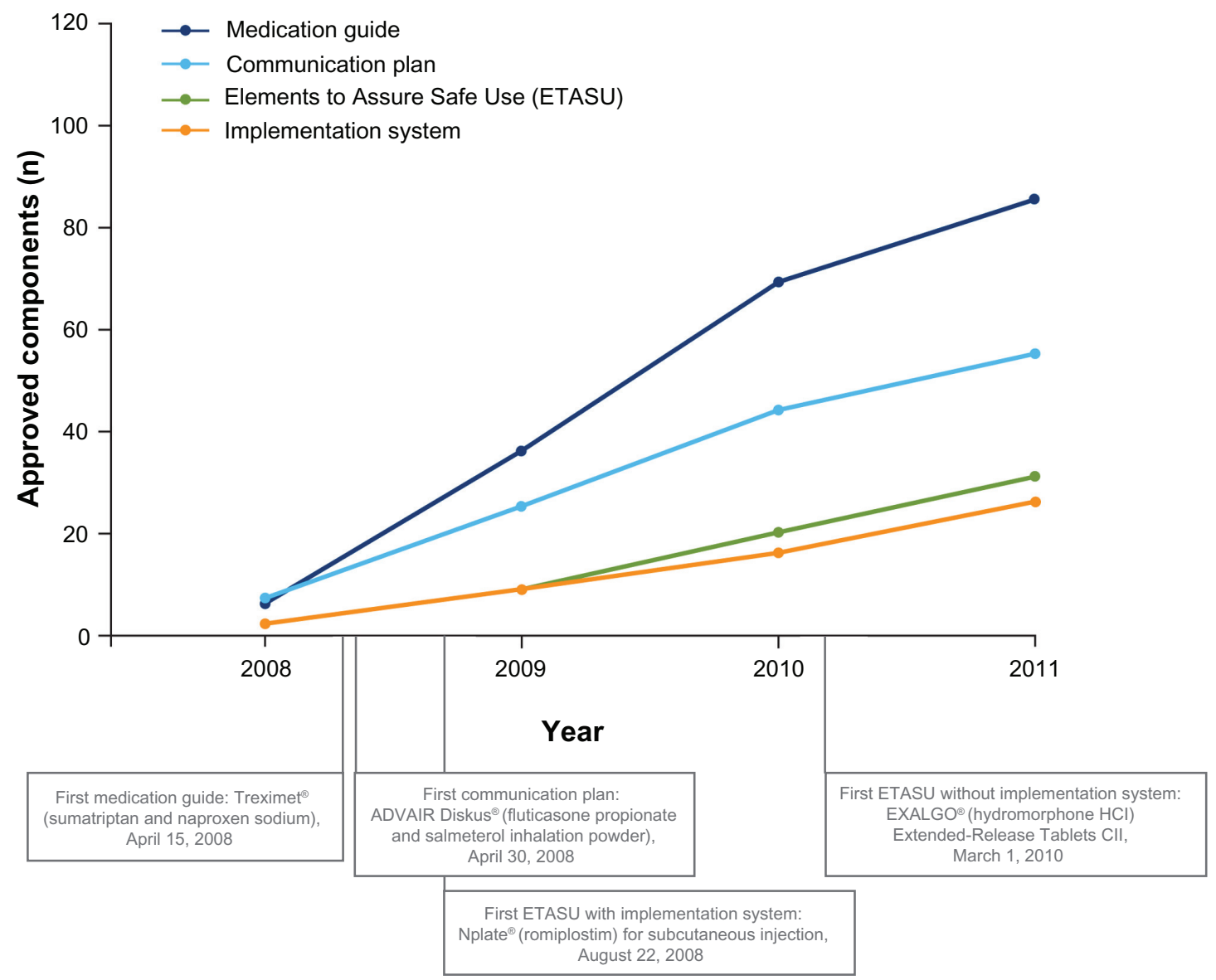

Figure 2 Cumulative approved Risk Evaluation and Mitigation Strategy (REMS) components, 2008-2011.29

Notes: Data based on Food and Drug Administration-approved REMS (last updated December 12, 20II). All approved REMS require a timetable for submission of assessments. A total of 199 products have been approved with REMS since $2008 ; 81$ products were subsequently released from a REMS and are not included here. ${ }^{29}$ 
The content of the class-wide medication guide may be similar to past ER opioid medication guides and outline symptoms of overdose and the risks associated with physically manipulating or tampering with the product (eg, breaking, chewing, or crushing the tablet), as well as the risk of sharing medications with others. ${ }^{31-33}$ Patients are also advised to store medications in a safe place to prevent theft or accidental exposure, and to dispose of unused medications properly. ${ }^{31-33}$ Most current sources suggest flushing unused medications down the toilet, or disposing of them in the trash in an inconspicuous manner. ${ }^{34,35}$ Furthermore, patients are instructed to report adverse events and are warned of the risks of concomitant use of other central nervous system depressants, alcohol, or illegal drugs. ${ }^{31-33}$

\section{Elements to assure safe use}

Manufacturers will be required to ensure that training is provided to all prescribers of ER opioids. ${ }^{12}$ The FDA has specified the content of the education program to include: (1) general information for safe opioid prescribing;

(2) product-specific information for each opioid within the class; and (3) patient counseling. ${ }^{12}$ To complement patient counseling, providers will be expected to utilize patient materials, including information on risks, safe use, and storage (Table 2). ${ }^{12}$ The potential content of the training program may be accessed at www.fda.gov/downloads/drugs/drugsafety/ information/bydrugclass/UCM251595.pdf. ${ }^{12}$

To implement provider training, manufacturers will fund and collaboratively develop a single set of educational materials applicable to all medications within the ER opioid class. However, training will likely be conducted by an accredited continuing medical education (CME) provider, where participants will be required to complete a subsequent knowledge assessment. ${ }^{12}$ This approach is intended to facilitate prescriber education and reduce the burden of this program on the health care system. ${ }^{8,12}$ Because there will be one set of training materials, providers will not have to complete separate educational materials and CME certification for each drug in this class. This may be analogous to the approach of the State of California, which requires all physicians to complete CME credits on pain management, appropriate care, and treatment of the terminally ill. ${ }^{36}$

Table 2 Provider training and patient education, class-wide REMS for ER opioids ${ }^{12}$

Provider training
Safe opioid prescribing
- Patient selection and assessment
- Pharmacokinetics, risks of addiction, abuse, misuse, and other considerations
- Managing patients who are taking opioids (eg, adherence, identifying drug-related
- aberrant behaviors)
- Initiating opioid therapy and dose titration
- Maintenance and reassessment over time
- Discontinuation of opioid therapy

- Discontinuation of opioid therapy

Product-specific information

- Pharmacokinetics and toxicity

- Requirements for opioid tolerance for ER formulations

- Individual product information and new product information

Patient counseling

- Product-specific information

- Adherence and proper administration

- Reporting adverse events

- Risk of tampering (eg, breaking, chewing, crushing)

- Risk of concomitant use with other central nervous system depressants, alcohol, or illicit drugs

- Risks of sharing, preventing overdose

- Proper storage, preventing accidental exposure

- Preventing theft/loss and avoiding unsafe exposure

- Discontinuation of opioid therapy

- Purpose/content of patient provider agreement

Note: aProviders will be expected to utilize patient education materials as part of counseling. Data from US Food and Drug Administration. ${ }^{12}$ Abbreviations: ER, extended release; REMS, Risk Evaluation and Mitigation Strategy.

\section{Patient counseling and education}

Patient materials ${ }^{\mathrm{a}}$

- Adherence and proper administration

- Reporting adverse events

- Risk of tampering (eg, breaking, chewing, crushing)

- Risk of concomitant use with other central nervous system depressants, alcohol, or illicit drugs

- Risks of sharing

- Symptoms of overdose

- Proper storage, preventing accidental exposure

- Preventing theft/loss and avoiding unsafe exposure

- Discontinuation of opioid therapy

- Purpose/content of patient provider agreement 


\section{Timetable for submission of assessments}

Regular and periodic assessments to determine whether the program is meeting the objectives and goals of REMS will be required for the class-wide ER opioid initiative. ${ }^{12}$ These assessments will provide the FDA and manufacturers with a tool for deciding whether this class-wide REMS should be modified to increase effectiveness. ${ }^{12}$

\section{Effect of the class-wide REMS}

Although training is presently voluntary for health care providers, it may eventually be mandatory for Drug Enforcement Administration licensing or renewal; however, this would require a congressional amendment to the Controlled Substances Act. ${ }^{14,37}$ Given the current rates of prescription opioid abuse and the need to minimize the serious risks associated with ER opioid formulations, active participation is essential. Although still under discussion between the FDA and manufacturers, there is the potential for providers to complete their class-wide REMS education in coordination with other general CME training in pain management. ${ }^{38}$

A key challenge of any effort to reduce risk is not overly restricting access for appropriate patients. The FDA has stated its intent to collaborate with the pain management community to ensure continued access to ER opioids after the implementation of the class-wide REMS. ${ }^{8}$ Ultimately, ensuring the success of these programs with continued access to these important medications will depend on the support of primary care and pain management providers and on collaboration among all stakeholders (ie, FDA, drug manufacturers or sponsors, CME providers, educators, and health care providers).

\section{Acknowledgment}

Technical editorial and writing assistance for the preparation of this manuscript was provided by Meg Church, Synchrony Medical, LLC, West Chester, PA. Funding for this support was provided by Mallinckrodt Inc, a Covidien company, Hazelwood, MO.

\section{Disclosure}

Dr Gudin reports serving as a consultant to Mallinckrodt Inc, a Covidien company, and serving on the speakers' bureau for Purdue Pharma LP, Pfizer Inc, Johnson \& Johnson Inc, and Endo Pharmaceuticals.

\section{References}

1. Chou R, Fanciullo GJ, Fine PG, et al. Opioid treatment guidelines: clinical guidelines for the use of chronic opioid therapy in chronic noncancer pain. J Pain. 2009;10(2):113-130.
2. Trescot AM, Helm S, Hansen H, et al. Opioids in the management of chronic non-cancer pain: an update of American Society of the Interventional Pain Physicians' (ASIPP) guidelines. Pain Physician. 2008; (special issue 11):S5-S62.

3. Governale L. Outpatient Prescription Opioid Utilization in the US, Years 2000-2009. US Food and Drug Administration; 2010. Available from: http:// www.fda.gov/downloads/AdvisoryCommittees/CommitteesMeetingMaterials/ Drugs/DrugSafetyandRiskManagementADvisoryCommittee/UCM220950. pdf. Accessed January 27, 2012.

4. Centers for Disease Control. National Vital Statistics System. Unintentional Drug Poisoning in the United States. Centers for Disease Control; 2010. http://www.cdc.gov/HomeandRecreationalSafety/pdf/ poison-issue-brief.pdf. Accessed January 27, 2012.

5. US Department of Health and Human Services. SAMHSA. Office of Applied Studies. Results from the 2009 National Survey on Drug Use and Health: National Findings. Volume 1. Summary of National Findings. http://oas.samhsa.gov/NSDUH/2k9NSDUH/2k9ResultsP. pdf. Accessed January 27, 2012.

6. Katz NP, Birnbaum HG, Castor A. Volume of prescription opioids used nonmedically in the United States. J Pain Palliat Care Pharmacother. 2010;24(2):141-144.

7. US General Accounting Office. Prescription Drugs, OxyContin Abuse and Diversion, and Efforts to Address the Problem. US General Accounting Office; 2003. http://www.gao.gov/new.items/d04110.pdf. Accessed January 27, 2012.

8. US Food and Drug Administration. Questions and answers: FDA requires a Risk Evaluation and Mitigation Strategy (REMS) for long-acting and extended-release opioids. US Food and Drug Administration; 2011. Available from: http://www.fda.gov/Drugs/DrugSafety/InformationbyDrugClass/ ucm251752.htm. Accessed January 27, 2012.

9. Martins SS, Storr CL, Zhu H, Chilcoat HD. Correlates of extramedical use of OxyContin versus other analgesic opioids among the US general population. Drug Alcohol Depend. 2009;99(1-3):58-67.

10. Reder RF, Oshlack B, Miotto JB, Benziger DD, Kaiko RF. Steady-state bioavailability of controlled-release oxycodone in normal subjects. Clin Ther. 1996;18(1):95-105.

11. Shram MJ, Sathyan G, Khanna S, et al. Evaluation of the abuse potential of extended release hydromorphone versus immediate release hydromorphone. J Clin Psychopharmacol. 2010;30(1):25-33.

12. US Food and Drug Administration. Post-approval REMS notification letter. http://www.fda.gov/downloads/Drugs/DrugSafety/ InformationbyDrugClass/UCM251595.pdf. Accessed January 27, 2012.

13. US Food and Drug Administration. Guidance for Industry: Format and Content of Proposed Risk Evaluation and Mitigation Strategies (REMS), REMS Assessments, and Proposed REMS Modifications. US Food and Drug Administration; 2009. Available from: http://www.fda. gov/downloads/Drugs/GuidanceComplianceRegulatoryInformation/ Guidances/UCM184128.pdf. Accessed January 27, 2012.

14. Office of National Drug Control Policy. Epidemic: responding to America's prescription drug abuse crisis. http://www. whitehousedrugpolicy.gov/publications/pdf/rx_abuse_plan.pdf. Accessed January 27, 2012.

15. Bohnert AS, Valenstein M, Bair MJ, et al. Association between opioid prescribing patterns and opioid overdose-related deaths. JAMA. 2011; 305(13):1315-1321.

16. Dunn KM, Saunders KW, Rutter CM, et al. Opioid prescriptions for chronic pain and overdose: a cohort study. Ann Intern Med. 2010;152:85-92.

17. Chabal C, Erjavec MK, Jacobson L, Mariano A, Chaney E. Prescription opiate abuse in chronic pain patients: clinical criteria, incidence, and predictors. Clin J Pain. 1997;13:150-155.

18. Katz N, Sherburne S, Beach M, et al. Behavioral monitoring and urine toxicology testing in patients receiving long-term opioid therapy. Anesth Analg. 2003;97:1097-1102.

19. Manchikanti L, Pampati V, Damron KS, et al. Prevalence of opioid abuse in interventional pain medicine practice settings: a randomized clinical evaluation. Pain Physician. 2001;4(4):358-365. 
20. Fishbain DA, Cole B, Lewis J, Rosomoff HL, Rosomoff RS. What percentage of chronic nonmalignant pain patients exposed to chronic opioid analgesic therapy develop abuse/addiction and/or aberrant drugrelated behaviors? A structured evidence-based review. Pain Medicine. 2008;9(4):444-459.

21. Fleming MF, Balousek SL, Klessig CL, Mundt MP, Brown DD. Substance use disorders in a primary care sample receiving daily opioid therapy. J Pain. 2007;8(7):573-582.

22. Fleming MF, Davis J, Passik SD. Reported lifetime aberrant drug-taking behaviors are predictive of current substance use and mental health problems in primary care patients. Pain Medicine. 2008;9(8):1098-1106.

23. Belgrade MJ, Schamber CD, Lindgren BR. The DIRE score: predicting outcomes of opioid prescribing for chronic pain. J Pain. 2006;7(9): $671-681$.

24. Butler SF, Budman SH, Fernandez K, Jamison RN. Validation of a screener and opioid assessment measure for patients with chronic pain. Pain. 2004;112:65-75.

25. Butler SF, Fernandez K, Benoit C, Budman SH, Jamison RN. Validation of the revised Screener and Opioid Assessment for Patients with Pain (SOAPP-R). J Pain. 2008;9(4):360-372.

26. Carrington Reid M, Engles-Horton L, Weber M, et al. Use of opioid medications for chronic noncancer pain syndromes in primary care. J Gen Intern Med. 2002;17:173-179.

27. Webster LR, Webster RM. Predicting aberrant behaviors in opioidtreated patients: preliminary validation of the Opioid Risk Tool. Pain Medicine. 2005;6(6):432-442.

28. Thalomid (thalidomide) capsules. Risk management plan. NDA 20-785. http://www.fda.gov/downloads/Drugs/DrugSafety/ PostmarketDrugSafetyInformationforPatientsandProviders/ UCM222649.pdf. Accessed January 27, 2012.

29. US Food and Drug Administration. Approved risk evaluation and mitigation strategies (REMS). December 12, 2011 update. http://www. fda.gov/Drugs/DrugSafety/PostmarketDrugSafetyInformationforPatientsandProviders/ucm111350.htm. Accessed January 27, 2012.

30. Joint Meeting of the Anesthetic and Life Support Drugs Advisory Committee and the Drug Safety and RiskManagementAdvisory Committee. http://www. fda.gov/downloads/AdvisoryCommittees/CommitteesMeetingMaterials/ Drugs/AnestheticAndLifeSupportDrugsAdvisoryCommittee/ UCM217510.pdf. Accessed January 27, 2012.
31. Medication guide. EXALGO (hydromorphone $\mathrm{HCl}$ ) Extended-release tablets. Hazelwood, MO: Mallinckrodt Inc, a Covidien company; 2010.

32. Medication guide. BUTRANS CIII (buprenorphine). Stamford, CT: Purdue Pharma LP; 2010.

33. Medication guide. OXYCONTIN (oxycodone hydrochloride controlledrelease) Tablets. Stamford, CT: Purdue Pharma LP; 2010.

34. US Food and Drug Administration. Medication disposal: questions and answers. http://www.fda.gov/Drugs/ResourcesForYou/Consumers/ BuyingUsingMedicineSafely/EnsuringSafeUseofMedicine/ SafeDisposalofMedicines/ucm186188.htm. Accessed January 27, 2012.

35. US Food and Drug Administration. Disposal of unused medicines: what you should know. http://www.fda.gov/Drugs/ ResourcesForYou/Consumers/BuyingUsingMedicineSafely/ EnsuringSafeUseofMedicine/SafeDisposalofMedicines/ucm 186187. htm. Accessed January 27, 2012.

36. Medical Board of California. New laws related to continuing medical education.http://www.mbc.ca.gov/licensee/continuing_education_laws. html. Accessed January 27, 2012.

37. US Food and Drug Administration. Controlled substances act. Title 21 - Food and drugs; Chapter 13 - Drug abuse prevention and control; Subchapter I - Control and enforcement. Part C - Registration of manufacturers, distributors, and dispensers of controlled substances. http://www.fda.gov/regulatoryinformation/legislation/ucm148726.htm. Accessed January 27, 2012.

38. US Food and Drug Administration. FDA opioid REMS meeting with industry, May 16, 2011. http://www.fda.gov/Drugs/DrugSafety/ InformationbyDrugClass/ucm258184.htm. Accessed January 27, 2012.

39. Fine PG, Portenoy RK. Ad Hoc Expert Panel on Evidence Review and Guidelines for Opioid Rotation. Establishing "best practices" for opioid rotation: conclusions of an expert panel. J Pain Symptom Manage. 2009; 38(3):418-425. 


\section{Appendix I}

Case study

Patient: 38-year-old male

Diagnosis: Low back pain

History: The patient has a 6-month history of severe low back pain following a work-related lifting injury. He has failed physical therapy, skeletal muscle relaxants, and epidural injections and is not a surgical candidate. He was switched to an ER opioid from hydrocodone/APAP, as his doses were escalating over time. Despite increases in the ER opioid dose over the last 2 months, he is failing to experience adequate pain relief. The patient has also been prescribed adjuvant medications, including anticonvulsants and antidepressants, and has a prior diagnosis of post-traumatic stress disorder.

Clinical considerations: Opioid treatment is not appropriate for all patients. It is important for the physician to order appropriate diagnostic tests to evaluate a patient's underlying pain condition. The physician should consider whether nonopioid therapy is likely to be effective. Patients who have moderate-to-severe pain that affects functioning or quality of life and who present with a favorable risk-benefit balance are most likely to be candidates for opioid therapy. ${ }^{1}$

All patients being considered for opioid therapy should provide a thorough history, including family history and disclosure of any psychosocial risk factors; patients must also undergo a physical examination and appropriate testing. In every case, this testing must include a thorough assessment of the patient's risk of substance misuse, abuse, or addiction. A number of brief assessment tools can be used to stratify patients according to risk, including the Opioid Risk Tool ${ }^{27}$ (ORT) and Screener and Opioid Assessment for Patients with Pain $^{25}\left(\mathrm{SOAPP}^{\circledR}-\mathrm{R}\right)$. Given that the patient is a young male with low back pain and psychiatric comorbidity, these assessment tools will likely indicate at least a moderate risk for abuse. If a trial of ER opioid therapy is being considered, the physician must evaluate the patient's recent opioid history. Most doses of ER opioids require that the patient be opioid tolerant, as defined by taking $60 \mathrm{mg} /$ day oral morphine or equivalent for at least 1 week. As the potency of ER opioids differs, the physician should take care to select the appropriate equianalgesic dose and account for incomplete cross-tolerance among opioids. This generally involves a reduction in the equianalgesic dose by $25 \%$ to $50 \%$ upon conversion to the new opioid. ${ }^{39}$ Once it is determined that the benefits of continued opioid therapy are likely to outweigh the risks, informed consent should be obtained. The physician should establish treatment goals and an opioid agreement that helps define treatment boundaries and monitor adherence. It is critical that the physician counsel the patient on the risks associated with opioids, such as respiratory depression, concomitant use of other central nervous system depressants, improper storage, and sharing medicine with others. Communicating product-specific information to the patient is also a key element to reduce overall risk. After treatment is initiated, periodic monitoring is important to assess tolerance, changes in symptoms, and abuse-related behaviors. If the patient exhibits aberrant behaviors (eg, lost prescriptions, unsanctioned dose escalations) that are predictive of abuse, the physician may want to consider comanagement or referral to a specialist. The physician should also consider whether discontinuing opioid therapy is a possibility. In summary, when considering a trial of opioid therapy, patient selection, counseling, and ongoing assessment are essential for mitigating risk.

\section{Appendix 2}

Commonly asked questions

\section{Which opioid medications fall under the class-wide REMS?}

All long-acting and ER opioids will be required to have a REMS under the new class-wide guidelines. These products include Avinza ${ }^{\circledR}$ (morphine sulfate extended-release capsules, CII; King Pharmaceuticals, Inc, Bristol, TN), Butrans ${ }^{\circledR}$ (buprenorphine transdermal system, CIII; Purdue Pharma LP, Stamford, CT), Dolophine ${ }^{\circledR}$ (methadone hydrochloride tablets, CII; Roxane Laboratories, Inc, Columbus, OH), Duragesic $^{\circledR}$ (fentanyl transdermal system, CII; Janssen Pharmaceuticals, Inc, Titusville, NJ), Embeda ${ }^{\circledR *}$ (morphine sulfate and naltrexone hydrochloride extended-release capsules, CII; King Pharmaceuticals, Inc), Exalgo ${ }^{\circledR}$ (hydromorphone $\mathrm{HCl}$ extended-release tablets, CII; Mallinckrodt Inc, Hazelwood, MO), Kadian ${ }^{\circledR}$ (morphine sulfate extended-release capsules, CII; Actavis Kadian LLC, Morristown, NJ), MS Contin ${ }^{\circledR}$ (morphine sulfate controlled-release tablets, CII; Purdue Pharma LP), Nucynta ${ }^{\circledR}$ ER (tapentadol extended-release tablets, CII; Janssen Pharmaceuticals, Inc), Opana ${ }^{\circledR}$ ER (oxymorphone hydrochloride extended-release tablets, CII; Endo Pharmaceuticals Inc, Chadds Ford, PA), Oramorph ${ }^{\circledR}$ SR (morphine sulfate sustained-release tablets, CII; Xanodyne Pharmaceuticals, Inc, Newport, KY), OxyContin ${ }^{\circledR}$ (oxycodone hydrochloride controlled-release tablets, CII; Purdue Pharma LP), and Palladone ${ }^{\circledR *}$ (hydromorphone 
hydrochloride extended-release capsules, CII; Purdue Pharma LP). Generic formulations of the above medications also require a REMS.

*Not currently marketed in the US.

\section{As a prescriber of long-acting and ER opioids, can I opt out of REMS?}

Although currently voluntary, completion of educational modules and a knowledge assessment will eventually be required in order to continue prescribing these medications.

\section{What are my obligations to patients under the class-wide REMS?}

Health care providers will be expected to counsel patients on the risks and safe use of prescription ER opioids (see Appendix 1: Case study). The class-wide REMS will provide educational materials that can be distributed to patients as part of patient counseling. Topics will include adherence and proper administration, safe use and storage of opioids, risks of sharing, risk of tampering (eg, breaking, chewing, crushing), reporting of adverse events, concomitant use with central nervous system depressants, symptoms of overdose, discontinuing opioids, and web links at which additional information may be found.

\section{Publish your work in this journal}

Therapeutics and Clinical Risk Management is an international, peerreviewed journal of clinical therapeutics and risk management, focusing on concise rapid reporting of clinical studies in all therapeutic areas, outcomes, safety, and programs for the effective, safe, and sustained use of medicines. This journal is indexed on PubMed Central, CAS
EMBase, Scopus and the Elsevier Bibliographic databases. The manuscript management system is completely online and includes a very quick and fair peer-review system, which is all easy to use. Visit http://www.dovepress.com/testimonials.php to read real quotes from published authors.

Submit your manuscript here: http://www.dovepress.com/therapeutics-and-clinical-risk-management-journal 